\title{
SU-8 as Hydrophobic and Dielectric Thin Film in Electrowetting-on-Dielectric Based Microfluidics Device
}

\author{
Vijay Kumar and N. N. Sharma \\ Mechanical Engineering Department, Birla Institute of Science and Technology, Pilani-333031, India \\ Correspondence should be addressed to N. N. Sharma, nitinipun@gmail.com
}

Received 29 November 2011; Accepted 13 February 2012

Academic Editor: Sanket Goel

Copyright (๑) 2012 V. Kumar and N. N. Sharma. This is an open access article distributed under the Creative Commons Attribution License, which permits unrestricted use, distribution, and reproduction in any medium, provided the original work is properly cited.

\begin{abstract}
Electrowetting-on-dielectric (EWOD) based droplet actuation in microfluidic chip is designed and fabricated. EWOD is used as on-chip micro-pumping scheme for moving fluid digitally in Lab-on-a-chip devices. For enabling this scheme, stacked deposition of thin dielectric and hydrophobic layer in that order between microchannel and electrodes is done. The present paper investigates the potential use of SU-8 as hydrophobic layer in conjunction of acting as dielectric in the device. The objective for the investigation is to lower the cost and a thin simplification in fabrication process of EWOD-based devices. We have done design and optimization of dimensions of electrode array including gap between arrays for EWOD micropump. Design and optimization are carried out in CoventorWare. The designing is followed by fabrication of device and analysis for droplet motion. The fabrication of the device includes array of electrodes over the silicon surface and embedding them in hydrophobic SU-8 layer. Water droplet movement in the order of microliter of spherical shape is demonstrated. It has been shown that an SU-8 microchannel in the current design allows microfluidic flow at tens of voltages comparable with costlier and more complicated to fabricate designs reported in the literature.
\end{abstract}

\section{Introduction}

Microfluidics is the technology of miniaturized analysis system for chemical and biological applications $[1,2]$. Many microfluidic devices have been studied and developed to handle fluids on the microscale [3]. In these devices, numerous actuation methods [4] like electrowetting, electrophoresis, electroosmosis, and thermocapillary have been reported to manipulate fluids in microdomains. EWOD has drawn much attention as a promising microfluidic actuation mechanism in micro total analysis system. Electrowetting (EWOD) has as excellent reversibility and it possesses a number of advantages over continuous flow system such as the ability to control each droplet independently, minimize the usage of fluidics, and reduce the mixing time. EWODbased microfluidics device, are used to manipulate droplet for splitting, mixing, and transporting $[4,5]$. Electrowetting system has advantage of low power consumption and fast operation. It has wide application not only in the Lab-onchip system [6] but also in the display and liquid sensor $[7,8]$.

In 1875 Lippmann [9] had shown the electrocapillary action to modify the shape of liquid droplet placed on the surface by application of voltage. Significant research since Lippmann has focused on understanding and optimizing the droplet actuation and contact angle behaviour. The focus of research in EWOD is towards reduction of power consumption, use of different dielectric materials, and optimization of device dimension. Existing EWOD microfluidics flow microchannel normally has Teflon coat as a hydrophobic layer [5-10]. The cost of Teflon is very high and its breakdown voltage is low. It is therefore desirable to deposit another dielectric material which can endure high voltage in conjunction with Teflon. Microchannels with Teflon have shown very good hydrophobicity with contact angle $120^{\circ}$ [10] and enabled microfluidic flow with 
TABLe 1: Design details of EWOD device.

\begin{tabular}{lc}
\hline Die sizes & $5.6 \times 5.6 \mathrm{~mm}^{2}$ \\
Reservoir size & $1.5 \times 1.5 \mathrm{~mm}^{2}$ \\
Electrode size & $1000 \times 100 \mu \mathrm{m}^{2}$ \\
Channel width $\left(W_{\mathrm{c}}\right)$ & $100 \mu \mathrm{m}$ \\
Channel length $\left(L_{\mathrm{c}}\right)$ & $1800 \mu \mathrm{m}$ \\
Channel height $(h)$ & $10 \mu \mathrm{m}$ \\
Number of electrodes & 6 \\
\hline
\end{tabular}

application of voltage in the order of tens of volts at dielectric thickness of $1 \mu \mathrm{m}$ [2]. A major issue in microfluidics flow-based electrowetting is high voltage which may cause excessive heating and evaporation of fluids in transport. The lowering of voltage requires reduction of Teflon thickness, but with thickness reduction of Teflon coat the possibility of breakdown occurs. To avoid such breakdowns, Teflon needs to combine with other dielectrics.

In the present work, actuation of fluid using EWOD is demonstrated in SU-8 channels of size $100 \mu \mathrm{m}$ wide and $10 \mu \mathrm{m}$ deep. The present design does not have Teflon coat on SU-8 layer. Moreover, in the present design the size of electrodes and gaps between electrodes is smaller than those reported in literature. Optimization of design in this work shows low applied voltage for fluid flow in bare SU8 channel, that is, without Teflon coating. The advantage of using bare SU-8 in microchannel is lowering the cost because of reduction of process steps, ease and wide range of bonding for capping of channel, and biocompatibility even at temperature above $260^{\circ} \mathrm{C}$ (temperature above which Teflon decomposes) [11].

The present work is organized in three more sections. Section 2 gives design and simulation of the device and is followed by section of fabrication and testing of the device. The last section gives conclusions and future scope of present work.

\section{Design and Simulation}

EWOD-based microchannel has been designed in CoventorWare Mask module. The complete die has the dimension of $5.6 \times 5.6 \mathrm{~mm}^{2}$. Microchannel design consists of six electrodes over which hydrophobic layer of SU-8 is coated. The design details are given in Table 1.

The SU-8 layer act as dielectric and solve the purpose of hydrophobic layer. The contact angle was measured in goniometer GBX DIGIDROP and was found to be $84 \pm 3^{\circ}$. The contact angle was measured for $15 \mu \mathrm{L}$ Droplet of DI water.

To verify the design, the modelling and simulation microfluidic flow have been carried out in CoventorWare. Liquid considered as DI water and the surface boundary conditions, solid volume, and fluid volume boundary condition used in simulation are shown in Figure 1. Electric potential at all electrodes was varied from $20 \mathrm{~V}$ to $150 \mathrm{~V}$. The liquid showed no movement below 70 volts and changes to vapour phase above $90 \mathrm{~V}$. Various combinations of shape, amplitude,
TABLE 2: Working voltage for combination of different dielectric in EWOD.

\begin{tabular}{|c|c|c|c|c|}
\hline S. no. & Dielectric 1 & Dielectric 2 & Voltage & Reference \\
\hline 1 & Parlyene & Teflon & $30-100 \mathrm{~V}$ & {$[2]$} \\
\hline 2 & $\begin{array}{c}\text { PECVD } \\
\text { Oxide }\end{array}$ & Teflon & $100 \mathrm{~V}$ & {$[12]$} \\
\hline 3 & $\mathrm{SiO}_{2}$ & Cytop & $85 \mathrm{Vac}$ & {$[13]$} \\
\hline 4 & Parlyene & Teflon & $80 \mathrm{~V}$ & {$[14]$} \\
\hline 5 & Parlyene & Teflon & 110 Vrms & {$[15]$} \\
\hline 6 & $\mathrm{SiO}_{2}$ & Teflon & $25-100 \mathrm{~V}$ & {$[16]$} \\
\hline 7 & $\mathrm{SiO}_{2}$ & Teflon & $45 \mathrm{~V}$ & {$[17]$} \\
\hline 8 & Parlyene & Teflon & $80-150$ Vrms & {$[18]$} \\
\hline 9 & $\mathrm{SiO}_{2}$ & Teflon & $50-200 \mathrm{~V}$ & [19] \\
\hline 10 & SU-8 & - & 70 & Present design \\
\hline
\end{tabular}

and phase difference of pulse for actuation of fluid were applied and tested. An optimal trapezoidal pulse phased out on consecutive electrodes triggered droplet movement at 75 volts. The pulse specifications as applied in simulations are shown in Figure 2.

Number of EWOD devices reported in the literature with different combination of dielectric material are listed and compared in Table 2 with the present design. The voltage variation with different combination of dielectric is in a range from $20 \mathrm{~V}$ to $150 \mathrm{~V}$. The present design is without Teflon and works at comparable voltage at which other EWOD device works.

Simulation and optimization of design carried out in CoventorWare were followed by device fabrication. The fabrication of the device and testing and validation of the design are given in next section.

\section{Fabrication and Testing}

Microchannels for EWOD actuation are fabricated using $\mathrm{Si}$ (100) substrate. A P type silicon wafer of 2 inch diameter and $<100>$ orientation was used in the fabrication. The resistivity of the wafer was 1-10 ohms-cm. The major fabrication steps are shown in Figure 4. Prior to loading sample for thermal oxidation, the standard cleaning of wafers RCA1 and RCA2 was performed.

Sample was loaded for thermal oxidation at $1100^{\circ} \mathrm{C}$ with a flow of nitrogen at atmospheric pressure. Initially, dry oxidation was performed for 15 minutes to realize the better contact or interface. Next, the wet thermal oxidation was performed at $100^{\circ} \mathrm{C}$ for 3 hours. Finally, again dry oxidation was performed for 15 minutes. All the wafers were unloaded at $500^{\circ} \mathrm{C}$ in nitrogen flow. Oxide thickness of sample was measured using ellipsometer followed by surface profile verification. Thickness of $\mathrm{SiO}_{2}$ layer has been found $495 \pm 3 \mathrm{~nm}$. The deposition of $\mathrm{Cr} / \mathrm{Au}$ was carried out in e-beam evaporation unit in high vacuum. A $99.9999 \%$ pure Gold $2 \mathrm{~cm}$ wire is used for evaporation. During the Evaporation the vacuum chamber of the order of $1.7 \mathrm{e}-6 \mathrm{mbar}$ was maintained. The estimated thickness of $\mathrm{Cr} / \mathrm{Au}$ was $20 / 200 \mathrm{~nm}$. The electrode having length of $1000 \times$ 


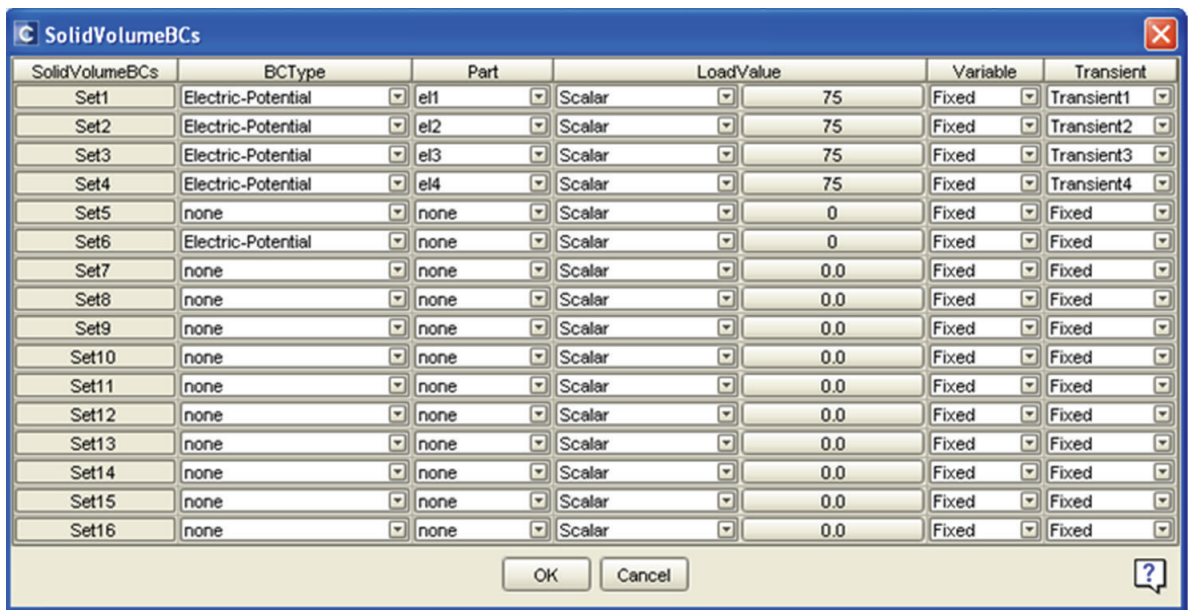

(a)

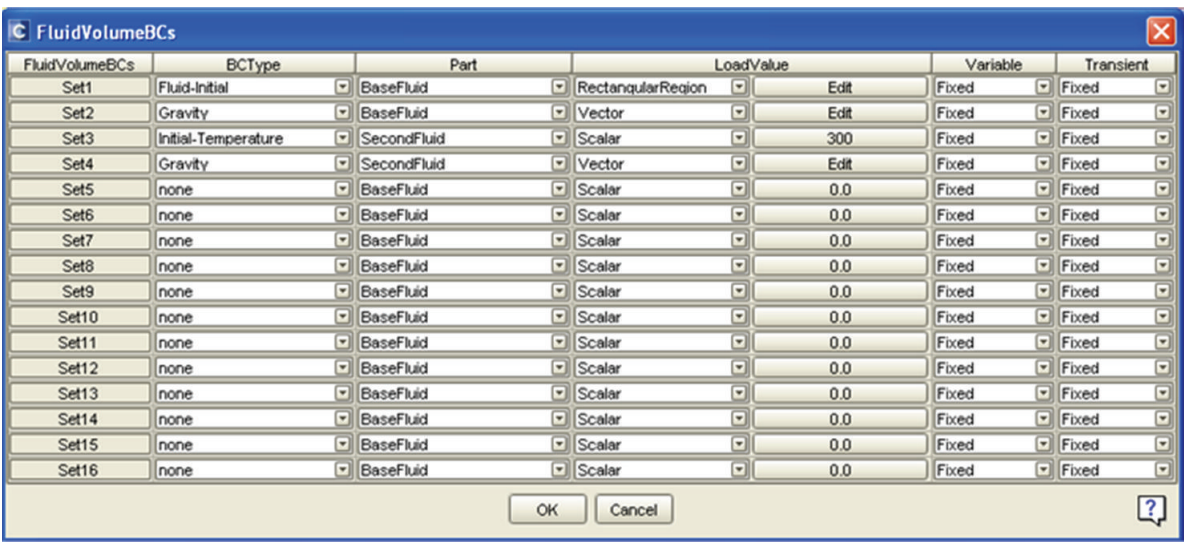

(b)

FIGURE 1: Surface and fluid boundary condition used in simulation.

100 um was delineated using optical photolithography. The S1813 positive photoresist was used for pattering the metal electrode. The photoresist was spin on $3000 \mathrm{rpm}$ for $30 \mathrm{sec}$ followed by baking at $70^{\circ} \mathrm{C}$ for 15 minutes. After exposure and development, the unwanted metal was etched out in Electronics grade $\mathrm{Cr} / \mathrm{Au}$ etchant. Refer to Figures 3(a) and $3(\mathrm{~b}))$.

SU-8 2000 series was used as insulating dielectric layer. SU-8 2000 is a high contrast epoxy-based photo resist designed for micromachining and other microelectronic applications, and it is used where a thick chemically and thermally stable pattern is desired. SU-8 2000 is an improved formulation of SU-8, which is widely used in MEMS for many years now. SU-8 resists have high functionality, high optical transparency, and are sensitive to UV radiation. SU-8 (2000.5) and SU-8 (2010) were used for fabrication of the microchannel. The SU-8 (2000.5) is used for thin film applications $\approx(0.5-1 \mu \mathrm{m})$ while SU-8 2010 is used for thick films $\approx(10-20 \mu \mathrm{m})$. The electrode arrays of gold and aluminium were fabricated over layer of $\mathrm{SiO}_{2}$. (refer to Figures 3(a) and 3(b)). The major fabrication steps are shown in Figure 4. SU-8 is used as insulating dielectric layer.
The thinnest available grade of SU-8 (MicroChem SU-8 2000.5) was deposited on electrodes by spin coating at 500 RPM for $5 \mathrm{~s}$ followed by 3000 RPM for $30 \mathrm{~s}$ and then softbaking on a hot plate at $70^{\circ} \mathrm{C}$ for $2 \mathrm{~min}$ and $90^{\circ} \mathrm{C}$ for $2 \mathrm{~min}$. Following exposure for $17 \mathrm{sec}$, the device is postbaked at $70^{\circ} \mathrm{C}$ for 2 minutes and $90^{\circ} \mathrm{C}$ for 4 minutes. This is then developed in SU-8 developer for $30 \mathrm{~s}$, rinsed with IPA and blow dried with nitrogen gas shown in Figure 4(c). Finally, the thick layer of SU-8 (MicroChem SU-8 2010) is subjected to photolithography for opening the channels with width of $100 \mu \mathrm{m}$. SU-8(2000.5) is not only used as dielectric layer but also used as hydrophobic Layer over the electrode.

Arrays of electrodes of different materials, namely, Gold, aluminium, and copper over silicon were examined for the microfluidics actuation with hydrophobic layer of bare SU8. Water droplet, in the order of microliter of spherical shape over the surface, moves by changing contact angle on application of voltage in the range of 60-80 volts.

The droplet movement was captured with optical microscope fitted with a digital camera and is shown in Figure 5. The net motion due to electrowetting was observed from initial placement with boundaries over first electrode (refer 


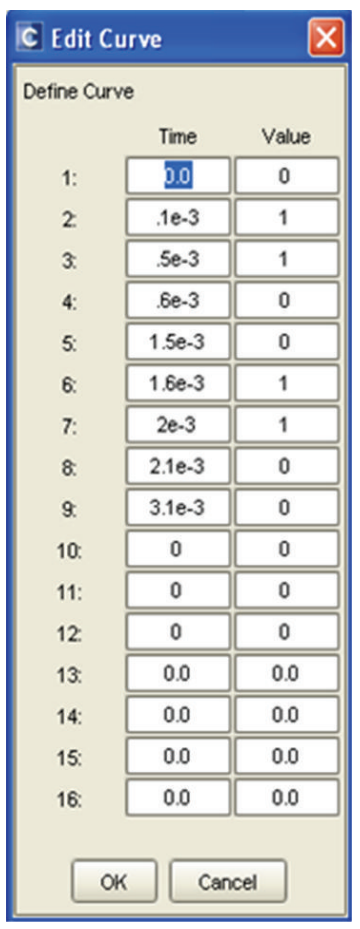

(a)

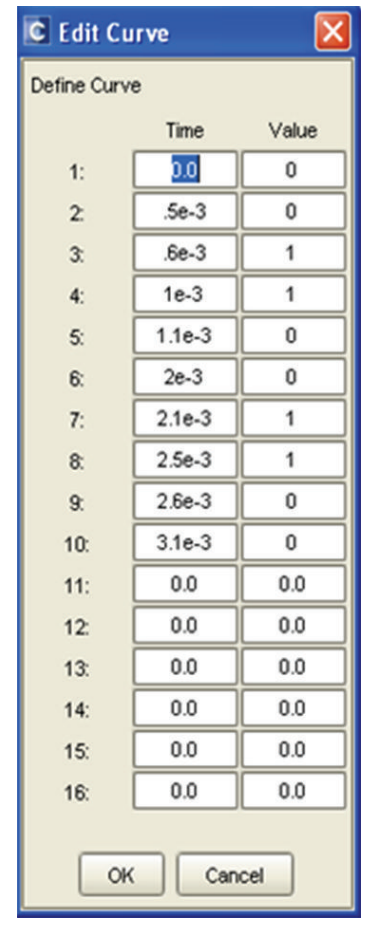

(b)

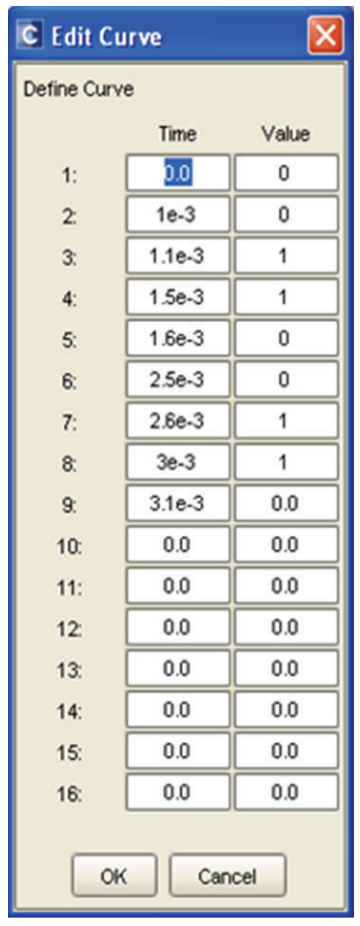

(c)

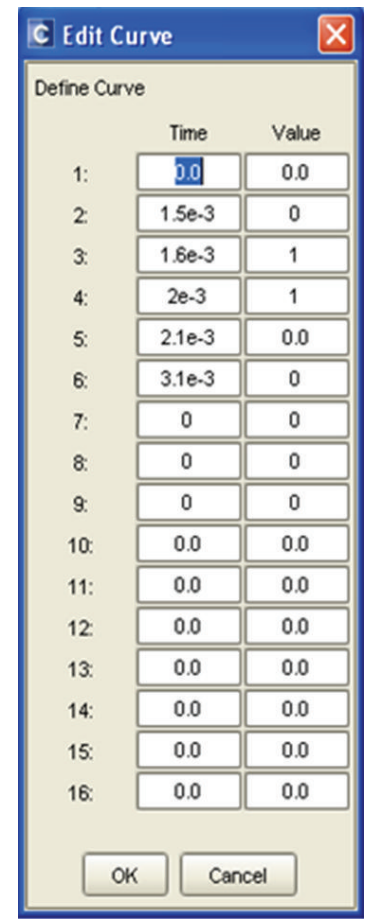

(d)

Figure 2: Trapezoidal pulse details used in simulation for triggering smooth droplet movement.

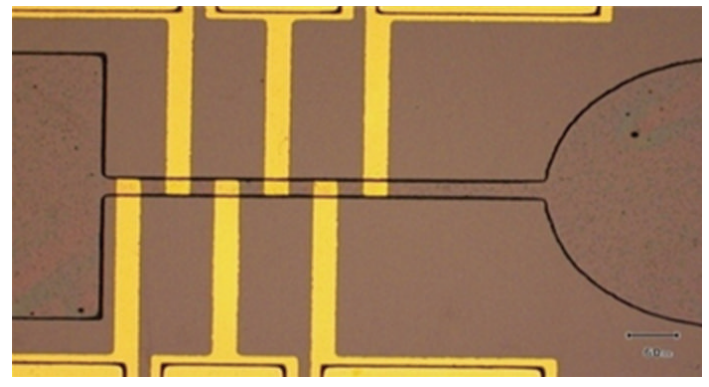

(a)

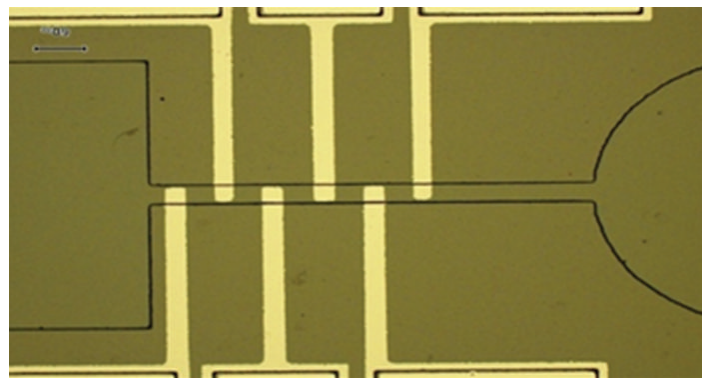

(b)

FIgURe 3: (a) Gold electrode in SU-8 (2010), (b) aluminium electrode in SU-8 (2010).

$\mathrm{Si}$

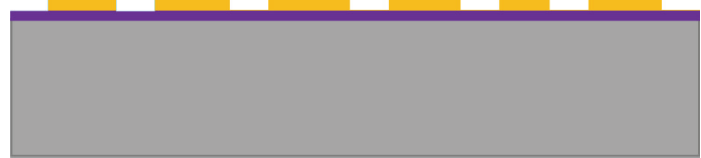

(a) $\mathrm{SiO}_{2}$

(b) $\mathrm{Cr} / \mathrm{Au}$ etching

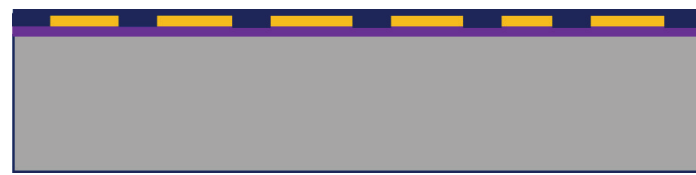

(c) Spin-coated SU-8 as dielectric

Figure 4: Process flow of EWOD device. 


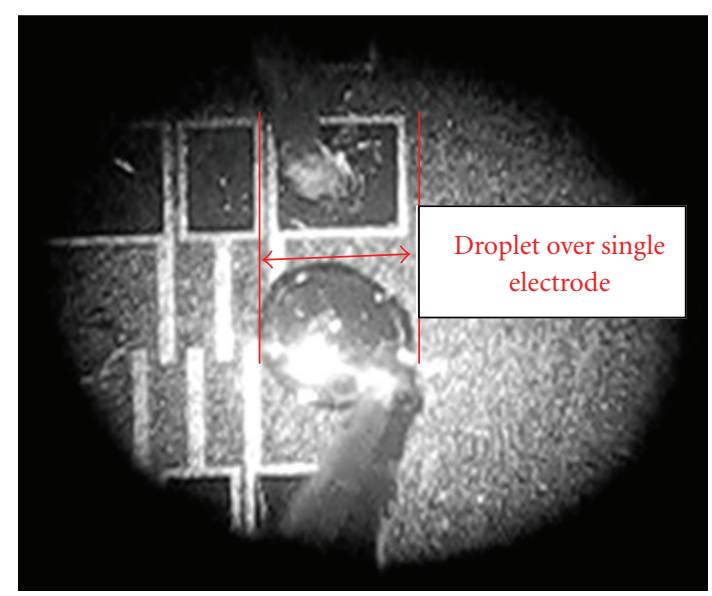

(a)

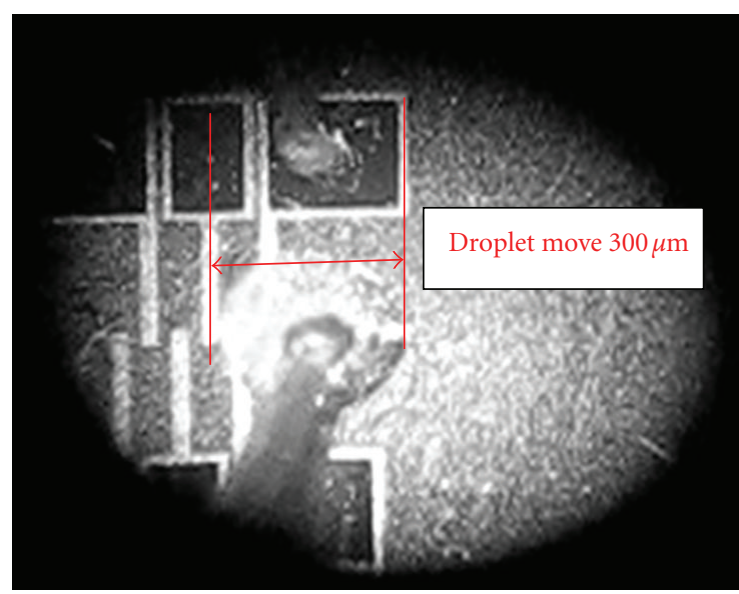

(b)

FIGURE 5: Photo of droplet (a) without application of voltage and (b) with application of voltage.

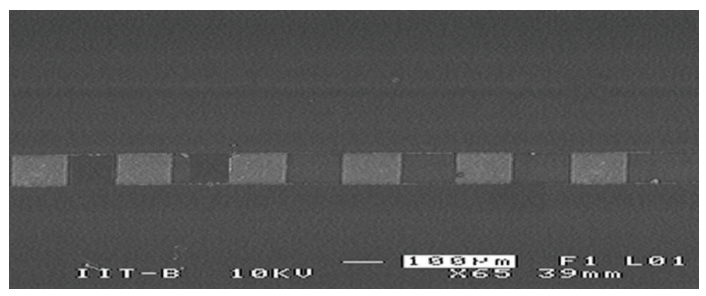

FIGURE 6: SEM of SU-8 (10 um depth) microchannel.

to Figure 5 (a)). The final spread causing movement in droplet reached to the third electrode which corresponds to a movement of $\sim 300 \mu \mathrm{m}$. The change of contact angles resulting into spread of drop in microchannel was observed when a voltage of 70 volts was applied with gold electrode. The applied voltage validates with simulated values mentioned in previous section.

No change or flow was observed when copper or aluminium was used as electrode even when the applied voltage was increased up to 220 volt. This may be attributed to higher resistivity of copper and aluminium leading to lesser strength of lines of electric field responsible for contact angle change of droplet. The exact reason needs to be further investigated.

The thickness of SU-8 was varied from $0.5 \mu \mathrm{m}$ to $5 \mu \mathrm{m}$. The droplet movement was observed with gold electrodes only but required higher voltage $(>100 \mathrm{~V})$ and show pinholes in SU-8 below $0.5 \mu \mathrm{m}$ thickness. The SEM graph of microchannel with gold electrodes embedded below SU-8 is shown in Figure 6.

\section{Conclusions}

The EWOD-based microfluidic flow with SU-8 as dielectric and as hydrophobic layer is designed, simulated, and fabricated using MEMS technology. The simulations were carried out in CoventorWare. The fabricated device is tested and the experimental results validate the simulation results. It has been shown that the device works well in comparable voltage range with those of Teflon coated microchannels. Teflon is costly and therefore present fabricated device suggests lowering of cost of EWOD-based microfluidic device by avoiding Teflon coating. The movement of the droplets in a controlled manner from the one electrode to another of the device is demonstrated.

The present work gives a low cost, robust, and biocompatible material in the form of SU- 8 which can be used in devices with EWOD. The method of EWOD micropumping is very useful in transport of fluid digitally in Lab-ona-chip kind of devices with metered quantity of fluid in microdomains. Currently, the authors are using the outcome of present work for development of Lab-on-a-chip device for testing for urinary tract infecting pathogens.

\section{Acknowledgment}

The authors would like to acknowledge the support from Centre of Excellence Nanoelectronics, Indian Institute of Technology, Bombay, for providing the facility for fabrication and characterization under Indian Nanoelectronics User Program.

\section{References}

[1] R. B. Fair, A. Khlystov, T. D. Tailor et al., "Chemical and biological applications of digital-microfluidic devices," IEEE Design and Test of Computers, vol. 24, no. 1, pp. 10-24, 2007.

[2] A. Wixforth, "Acoustically driven programmable microfluidics for biological and chemical applications," Journal of the Association for Laboratory Automation, vol. 11, no. 6, pp. 399405, 2006.

[3] C. G. Cooney, C. Y. Chen, M. R. Emerling, A. Nadim, and J. D. Sterling, "Electrowetting droplet microfluidics on a single planar surface," Microfluidics and Nanofluidics, vol. 2, no. 5, pp. 435-446, 2006.

[4] R. B. Fair, V. Srinivasan, H. Ren, P. Paik, V. K. Pamula, and M. G. Pollack, "Electrowetting-based on-chip sample processing 
for integrated microfluidics," in IEEE International Electron Devices Meeting, pp. 779-782, December 2003.

[5] R. Miraghaie, J. D. Sterling, and A. Nadim, "Shape oscillation and internal mixing in sessile liquid drops using electrowetting-on-dielectric (EWOD)," in NSTI Nanotechnology Conference and Trade Show (NSTI Nanotech '06), pp. 610-613, May 2006.

[6] R. B. Fair, "Digital microfluidics: Is a true lab-on-a-chip possible?" Microfluidics and Nanofluidics, vol. 3, no. 3, pp. 245281, 2007.

[7] R. Shamai, D. Andelman, B. Berge, and R. Hayes, "Water, electricity, and between on electrowetting and its applications," Soft Matter, vol. 4, no. 1, pp. 38-45, 2007.

[8] K. Zhou, J. Heikenfeld, K. A. Dean, E. M. Howard, and M. R. Johnson, "A full description of a simple and scalable fabrication process for electrowetting displays," Journal of Micromechanics and Microengineering, vol. 19, no. 6, Article ID 065029, 2009.

[9] F. Mugele and J. C. Baret, "Electrowetting: from basics to applications," Journal of Physics Condensed Matter, vol. 17, no. 28, pp. R705-R774, 2005.

[10] H. Moon, S. K. Cho, R. L. Garrell, and C. J. Kim, "Low voltage electrowetting-on-dielectric," Journal of Applied Physics, vol. 92, no. 7, p. 4080, 2002.

[11] G. Voskerician, M. S. Shive, R. S. Shawgo et al., "Biocompatibility and biofouling of MEMS drug delivery devices," Biomaterials, vol. 24, no. 11, pp. 1959-1967, 2003.

[12] J. Lee, H. Moon, J. Fowler, T. Schoellhammer, and C. J. Kim, "Electrowetting and electrowetting-on-dielectric for microscale liquid handling," Sensors and Actuators A, vol. 95, no. 2-3, pp. 259-268, 2002.

[13] U. C. Yi and C. J. Kim, "Soft printing of droplets pre-metered by electrowetting," Sensors and Actuators A, vol. 114, no. 2-3, pp. 347-354, 2004.

[14] M. G. Pollack, R. B. Fair, and A. D. Shenderov, "Electrowetting-based actuation of liquid droplets for microfluidic applications," Applied Physics Letters, vol. 77, no. 11, pp. 17251726, 2000.

[15] M. J. Schertzer, R. Ben-Mrad, and P. E. Sullivan, "Using capacitance measurements in EWOD devices to identify fluid composition and control droplet mixing," Sensors and Actuators B, vol. 145, no. 1, pp. 340-347, 2010.

[16] S. K. Cho, H. Moon, J. Fowler, and C. J. Kim, "Splitting a liquid droplet for electrowetting-based microfluidics," in ASME International Mechanical Engineering Congress and Exposition, November 2001.

[17] J. Wu, R. Yue, X. Zeng, and L. Liu, "Droplets actuating chip based on electrowetting-on-dielectric," Frontiers of Electrical and Electronic Engineering in China, vol. 2, no. 3, pp. 345-349, 2007.

[18] A. R. Wheeler, E. M. Miller, I. Barbulovic-Nad, and V. N. Luk, "Digital microfluidics for screening assays," in 12th International Conference on Miniaturized Systems for Chemistry and Life Sciences, pp. 763-765, 2008.

[19] N. Howell and W. Li, "Modeling and simulation of droplet translocation and fission by electrowetting-on-dielectrics (EWOD)," Frontiers of Mechanical Engineering in China, vol. 5, no. 4, pp. 376-388, 2010. 

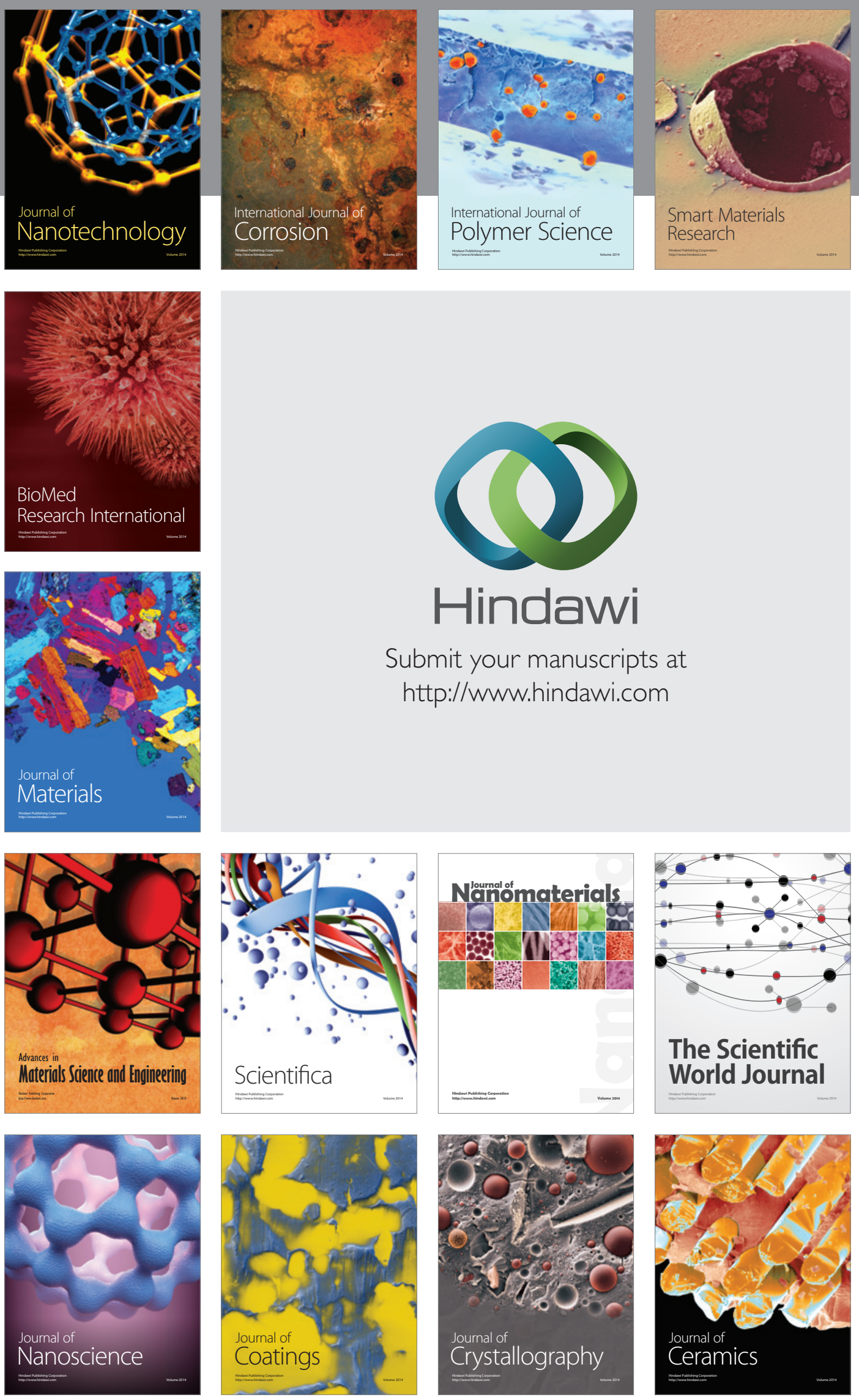

The Scientific World Journal

Submit your manuscripts at

http://www.hindawi.com

\section{World Journal}

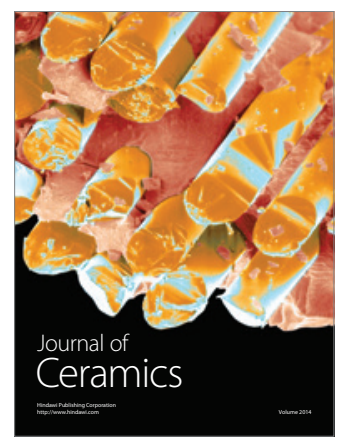

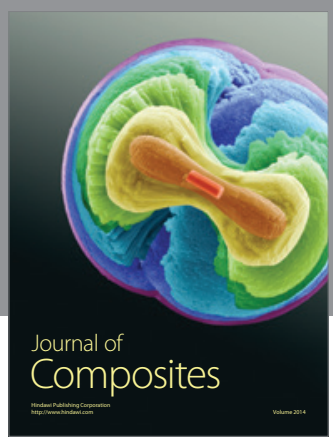
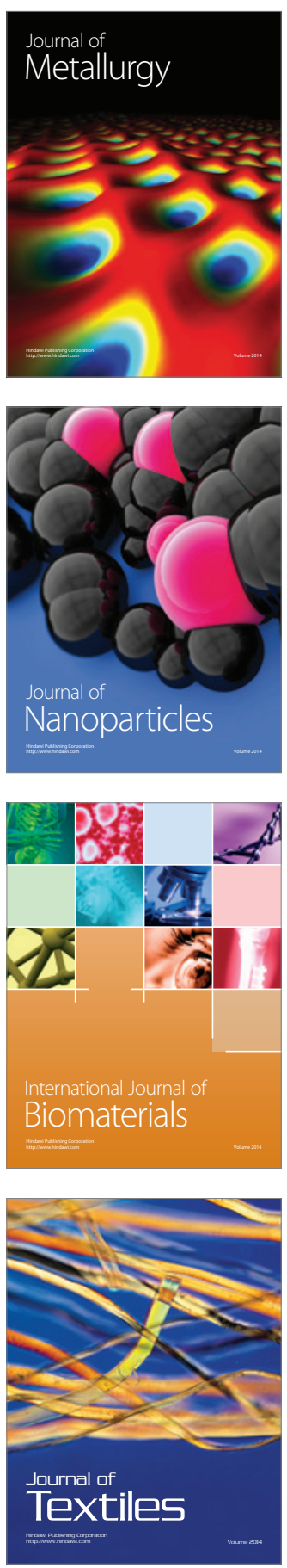